\title{
Ruptured subcapsular hepatic hematoma complicating severe preeclampsia with haemolysis, elevated liver enzymes, low platelet count syndrome: a case report
}

\author{
Ashok R. Anand, Binita H. Shah*, Pratibha Vashisth
}

Department of Obstetrics and Gynaecology, Grant Government Medical College and Sir JJ Group of Hospitals, Mumbai, Maharashtra, India

Received: 19 August 2020

Revised: 01 October 2020

Accepted: 02 October 2020

\section{*Correspondence:}

Dr. Binita H. Shah,

E-mail: binitashah693@gmail.com

Copyright: (c) the author(s), publisher and licensee Medip Academy. This is an open-access article distributed under the terms of the Creative Commons Attribution Non-Commercial License, which permits unrestricted non-commercial use, distribution, and reproduction in any medium, provided the original work is properly cited.

\section{ABSTRACT}

Subcapsular liver hematoma is rare complication of severe preeclampsia and HELLP syndrome, thus making it essential for these patients to be followed up in critical and intensive care units for advanced medical support with fluid and electrolyte management and replacement of blood products while treating underlying disorders. Treatment options have to be individualised and vary from conservative management to surgical treatment including hepatic resection, hepatic artery ligation, and liver transplantation. In this paper we report a case of ruptured hepatic hematoma in a 35 year old female, few hours within delivery, a complication of severe preeclampsia and HELLP syndrome

Keywords: Subcapsular hepatic hematoma, HELLP syndrome, Disseminated intravascular coagulation

\section{INTRODUCTION}

Subcapsular liver hematoma (SLH) has been reported in less than $2 \%$ of pregnancies complicated by HELLP syndrome (hemolysis, elevated liver enzymes, and low platelets) and preeclampsia. The incidence of SLH ranges from $1 / 40.000$ to $1 / 250.000$, causing increased risk of maternal morbidity and perinatal mortality., ${ }^{1,2}$ The symptoms of SLH may present as pain in epigastric region , right upper quadrant or shoulder pain, abdominal distension, nausea and vomiting. SLH may result in hepatic rupture thus causing life threatening problems such as disseminated intravascular coagulation (DIC), acute liver, and kidney failure and hence lead to maternal mortality.

\section{CASE REPORT}

A 35 years old female, gravida 2 abortion 1, with 9 months gestational age, BD 37.2 weeks, BS 38 weeks (13 weeks scan), registered and immunized at a primary health care center was referred to our tertiary care center in view of preeclampsia with impending eclampsia. Patient was complaining of pain in abdomen. Patient had already received a loading dose of injection $\mathrm{MgSO} 4$, tablet labetalol $100 \mathrm{mg}$ and tablet nifidepin $10 \mathrm{mg}$ in the primary health care centre before being transferred. On examination, her general condition was moderate, afebrile with $\mathrm{P}$; 92/min BP; 150/90 $\mathrm{mmHg}$, pallor; positive, bl grade 2 pedal edema, facial puffiness; positive, UA trace, no pmss, deep tendon reflexes absent, hematuria; positive. Patient did not have any icterus, petechia, purpura CVS RS NAD, p/a obesity; positive, free fluid; positive, ut 30-32 weeks, fhs was not localized, scar of sx; positive, no sct. Ps no bleed no leak pv os 2.5 $\mathrm{cm}$ dilated, 30 effaced, memb; positive. Patient had past $\mathrm{h} / \mathrm{o}$ ovarian cystectomy with myomectomy done in 2017 , h/o appendicectomy in 2003. h/o PIH in present pregnancy since January 2020, not on any anti hypertensives. Urgent ultrasound was done s/o intra 
uterine fetal demise of 36 weeks with cephalic presentation with anterior placenta with $2.7 \mathrm{Kg} \mathrm{BW}$, with liver-subcapsular hematoma of $3.5 \mathrm{~cm}$ in maximum thickness and with gross ascites. Laboratory investigations were done with $\mathrm{Hb} 7.3 \mathrm{gm} \%$, tlc 10.96, plt $73 \mathrm{k}$, Bili 2.1, SGOT, 222 SGPT 125, creat 0.9, urea 32, Pt 25.8, inr 1.38, aptt 61, Na 131, K 6.0, RBS 115, Ca 10.4, Mg 5.40. Blood group was B positive and $\mathrm{HHH}$ negative. Patient went into labour spontaneously and delivered a still birth of $2.4 \mathrm{Kg}$. Immediate post delivery the patient was vitally stable, p 94/min, bp 120/80 $\mathrm{mmHg}$.

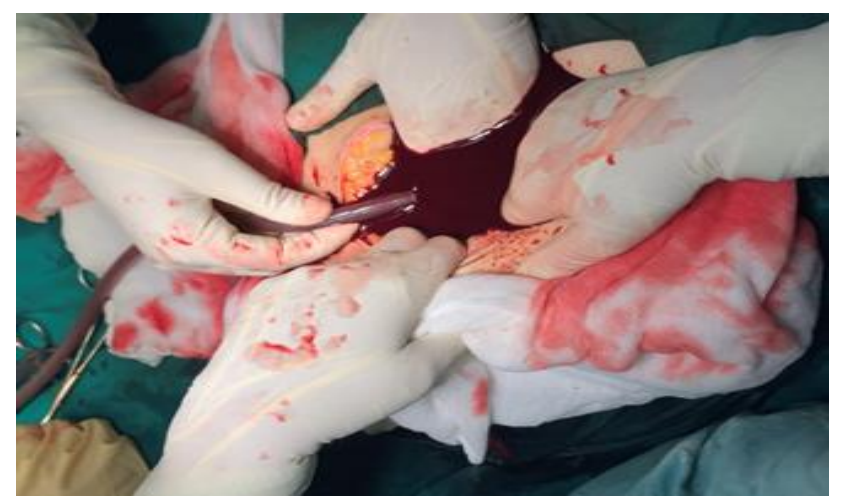

Figure 1: Hemoperitoneum.

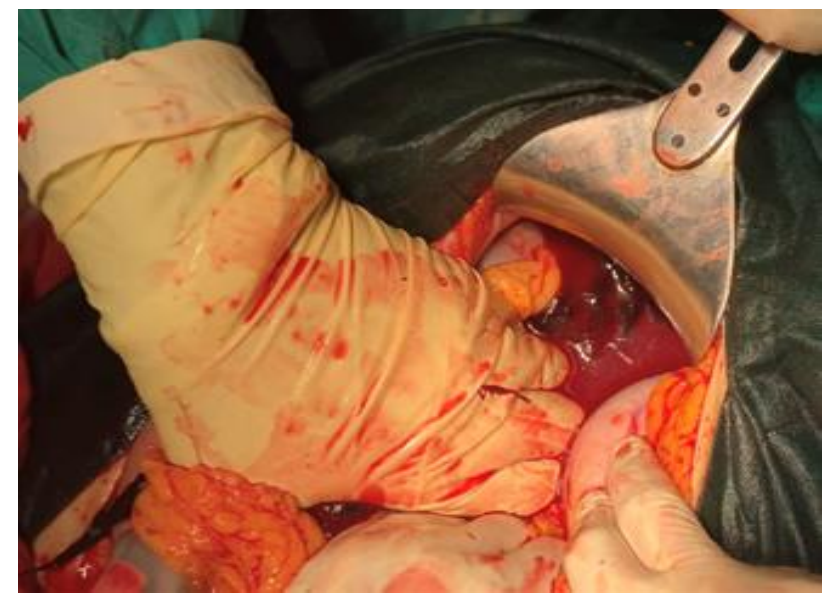

Figure 2: Large subcapsular liver hematoma.

Uterus was well contracted, ag $112 \mathrm{~cm}$, ua trace, hematuria also cleared, did not have any pre monitoring signs and symptoms, dtr normal. Post delivery $\mathrm{Hb} 6.9$ gm\%, tlc 10.3, plt 70k, Bili 1.5, SGOT 600, SGPT 246, pt 18.9, inr 1.6, aptt 56. Liver enzymes were in a rising trend. 8 units FFP and 1 pint blood transfusion was started. Within $2 \mathrm{hrs}$ the ag increased to more than 116 $\mathrm{cm}$ (more than $4 \mathrm{~cm}$ rise) with increasing pallor, $p$ $140 / \mathrm{min}$, bp $110 / 70 \mathrm{mmHg}$, tachypnoea was positive, rr $22 /$ min. Urgent USG $(A+P)$ s/o increasing size of liver hematoma $>3.8 \mathrm{~cm}$ in thickness. Immediate diagnostic tapping was done suggestive of hemorrhagic tap. Decision was taken for an emergency exploration. Emergency exploratory laparotomy with evacuation of subcapsular hematoma with hemoperitoneum drainage was done in GA.

A Midline vertical incision $5 \mathrm{~cm}$ superior and $5 \mathrm{~cm}$ inferior to umbilicus from pubic symphysis to epigastrium was taken. Suction of hemoperitoneum done from abdomen, first from left pelvis all collected blood suctioned out, then right pelvis all collected blood suctioned out, approximately 3 litres of hemoperitoneum was present. On intra operative examination Uterus was well contracted and had no bleeding. Incision extended to xiphisternum and falciform ligament released. Right sided subcostal region elevated with retractor, large subcapsular hematoma seen over superior anterior and lateral region of liver with breech in liver capsule. Evacuation of hematoma (approximate $960 \mathrm{gm}$ ) done with finger dissection.

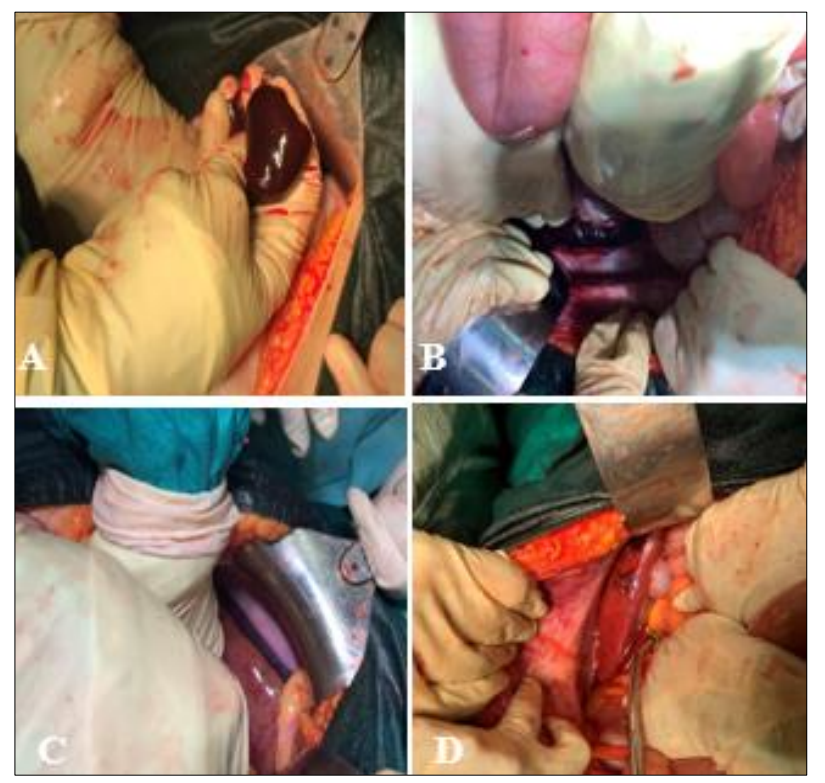

Figure 3: Evacuation of hematoma with finger dissection.

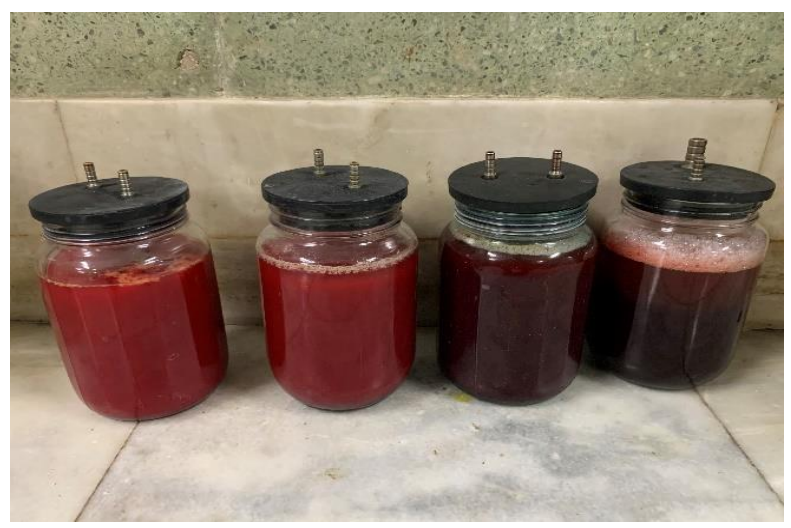

Figure 4: Three litres of hemoperitoneum.

Adrenalin soaked gauze placed on anterior, superior and lateral surface of liver .Compression given for 5-10 
minutes. Feracylium hemostatic solution and gel foam applied. Splenic surface appeared normal on examination. Abdomen was closed and 2 drains were placed; 32f ADKD placed in sub hepatic region, 28F ADKD in left pelvis. 4 pints whole blood and 4 units FFP given intra operatively. Patient was shifted to ccu with ventilatory support for observation. 1 pint whole blood and 4 units FFP given in post operative period.

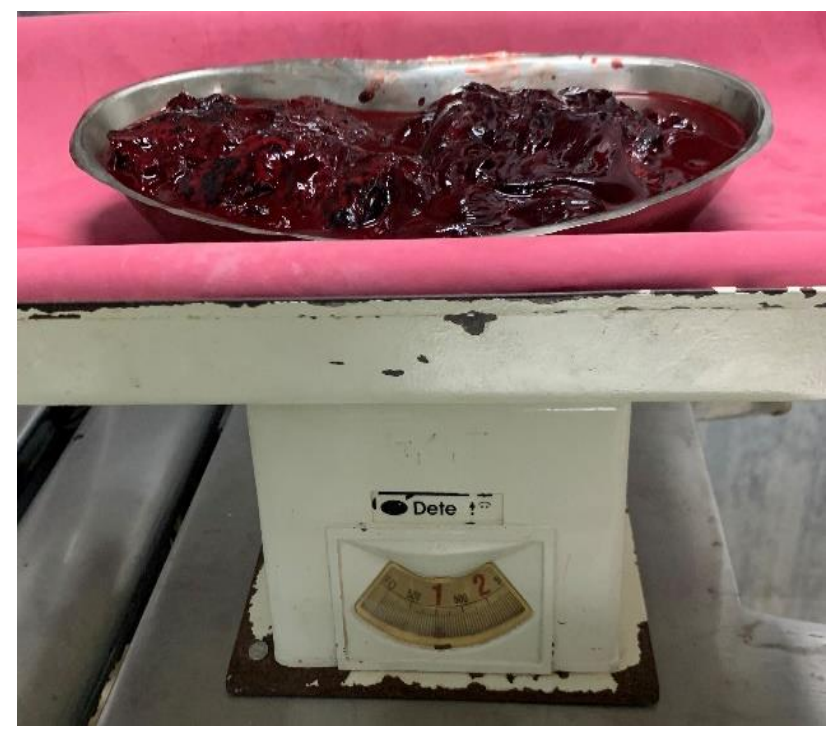

Figure 5: Approximately 930 grams of hematoma.

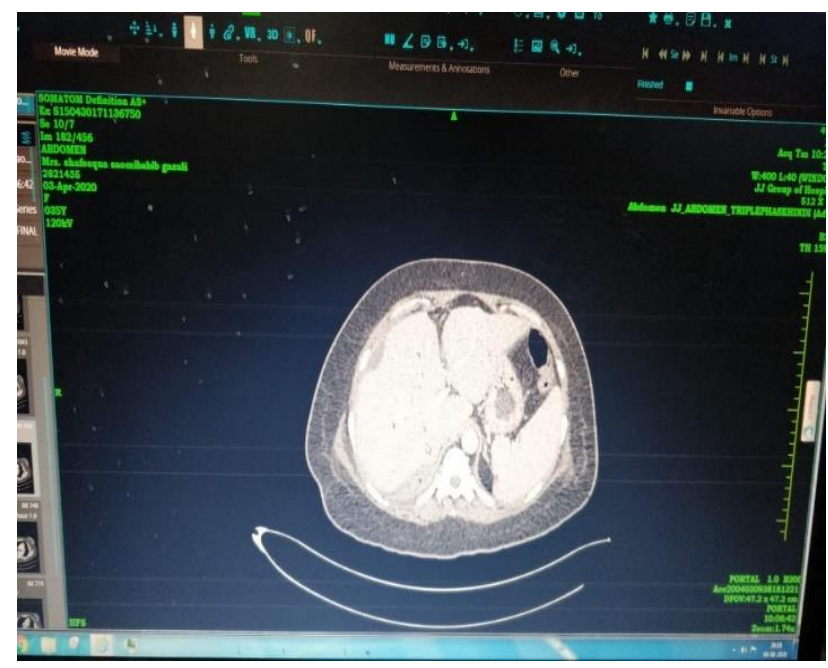

Figure 6: Resolving hematoma as seen in CT.

Patient was vitally stable and extubated on next day. Patient was started on higher antibiotics and kept nil by mouth for 3 days. On 4th day USG $(\mathrm{A}+\mathrm{P})$ done s/o subcapsular hematoma of $15 \mathrm{~mm}$ thickness, decreasing in size, with minimal free fluid between bowels. On 5th day CECT $(\mathrm{A}+\mathrm{P})$ was done s/o mild hepatomegaly with subcapsular hematoma in right lobe of liver, mildly bulky uterus with endometrial collection, minimal free fluid in abdomen and pelvis. Drain output also reduced to $<25$ $\mathrm{ml} /$ day and hence drain removed after 7 days. Laboratory results also normalized with $\mathrm{Hb} 8.1 \mathrm{gm} \%$, tlc 12450, plt
291, bili. 0.4, ot/pt 19/56, creat 0.7 , urea 20, Pt 15, Inr 1.15.The patient was then discharged.

\section{DISCUSSION}

HELLP syndrome occurs in approximately $0.5 \%-0.9 \%$ of all pregnancies most commonly during antenatal period and SLH occurs in about 1- $2 \%$ of all preeclampsia cases and HELLP syndrome. ${ }^{3}$ The incidence of SLH has been reported to be higher in those with advanced maternal age. Subcapsular hematoma of liver is the accumulation of blood between the Glissons capsule and the liver parenchyma, first described by Abercombie in $1844 .{ }^{4}$ It has been reported that preeclamptic syndrome causes fibrin deposition, hypovolaemia, infarction and ischemia of liver thus causing haemorrhage and SLH. The continuous expansion of the SLH may induce the rupture of the hepatic capsule in case of trauma such as during palpation of abdomen, transport of the patient, manual removal of the placenta and even uterine contractions have been hypothesized as the underlying cause. ${ }^{5}$ Clinically, pain in the epigastric region or pain in right upper quadrant of shoulder with nausea, vomiting, and abdominal distension are the few signs and symptoms. In case there is a rupture of hepatic subcapsular hematoma, signs of hemodynamic compromise start to develop. ${ }^{6}$ This must be followed up with hemodynamic and coagulation parameters during the management of the patient. Ultrasound of the abdomen and pelvis is the first choice of non invasive tool for diagnosis and evaluation. ${ }^{7}$ CT and MRI could be used in order to elucidate the diagnosis in ambiguous cases. Patients who are hemodynamically stable can be managed conservatively by means of intensive medical support with infused fluid, replacement of blood and blood products, and treatment of HELLP syndrome and preeclampsia. Advanced procedures like percutaneous transcatheter hepatic artery embolization could be a useful alternative procedure that could effectively control hemorrhage. ${ }^{7}$ However if patient is hemodynamically unstable, urgent surgery may be required. Novel operative techniques such as hemostatic mesh can be used for the bleeding surface of liver and the omentum can be sutured to the bleeding surface. ${ }^{8}$ Bleeding surfaces can be packed with collagen fleece and perihepatic space should be drained. If the hemorrhage is not controlled with conservative or with surgical techniques and acute liver failure occurs, liver transplantation should be considered. ${ }^{9}$ Ultrasound of the abdomen, CT, and MRI are useful imaging tools included in the postpartum follow-up until the resolution of the hematoma. ${ }^{8}$ In our case clinical symptoms in combination with the deranged liver function tests raised suspicion for the diagnosis. As the hemodynamic status of our patient was deteriorating, emergency surgery with evacuation of liver hematoma and drainage of hemoperitoneum was done

Early diagnosis and management could decrease maternal morbidity and mortality in such cases. 


\section{CONCLUSION}

Subcapsular hematoma of liver with HELLP syndrome and severe preeclampsia is a rare but dangerous clinical entity. Vigilant monitoring of these patients with HELLP syndrome by advanced techniques of imaging in pre as well as postpartum period is mandatory. If the patient is vitally unstable, surgical management should be considered as the first choice of treatment.

Funding: No funding sources

Conflict of interest: None declared

Ethical approval: Not required

\section{REFERENCES}

1. Dyke RW. The liver in pregnancy in Hepatology: A Text Book of Liver Disease. 2nd ed. Newyork: Wiley \& Sons; 1990:1408-8.

2. Westengaard L. Spontaneous rupture of the liver in pregnancy. Acta Obstet Gynecology. 1983;59:55961.

3. Haram K, Svendsen E, Abildgaard U. The HELLP syndrome: clinical issues and management. A Review. BMC Pregnancy Childbirth. 2009;9:8.

4. Abercrombie J. Case of hemorrhage of the liver. London Medical Gazette. 1844;34:792-4.

5. Dessole S, Capobianco G, Virdis P, Rubattu G, Cosmi E, Porcu A. Hepatic rupture after cesarean section in a patient with HELLP syndrome: a case report and review of the literature. Archives of Gynecology and Obstetrics. 2007;276(2):189-92.

6. Ndzengue A, Hammoudeh F, Brutus P, Ajah O, Purcell R, Leadon J, et al. An obscure case of hepatic subcapsular hematoma. Case Rep Gastroenterol. 2011;5(1):223-26.

7. Cernea D, Dragoescu A, Novac M. HELLP syndrome complicated with postpartum subcapsular ruptured liver hematoma and purtscher-like retinopathy. Case Reports in Obstetrics and Gynecology. 2012;2012:4.

8. Carlson KL, Bader CL. Ruptured subcapsular liver hematoma in pregnancy: a case report of nonsurgical management. Am J Obstet Gynecol. 2004;190(2): 558-60.

9. Barton JR, Sibai BM. Care of the pregnancy complicated by HELLP syndrome. Gastroenterology Clinics of North America.1992;21(4):937-50.

Cite this article as: Anand AR, Shah BH, Vashisth P. Ruptured subcapsular hepatic hematoma complicating severe preeclampsia with haemolysis, elevated liver enzymes, low platelet count syndrome: a case report. Int J Reprod Contracept Obstet Gynecol 2020;9:4726-9. 